\title{
Discovering Digital Technology Training Challenges for Future-Ready Educator: A Preliminary Study from Trainer Perspective
}

\author{
Farah Zeehan ${ }^{1, *}$, Rose Alinda Alias², Zaidatun Tasir ${ }^{3}$ \\ ${ }^{1}$ Scholarship and Sponsorship Division, Ministry of Education, Indonesia \\ ${ }^{2}$ School of Azman Hashim International Business, Universiti Teknologi Malaysia, Malaysia \\ ${ }^{3}$ Faculty of Social Sciences and Humanities, Universiti Teknologi Malaysia, Malaysia
}

Received October 24, 2019; Revised January 21, 2020; Accepted February 25, 2020

Copyright $\bigcirc 2020$ by authors, all rights reserved. Authors agree that this article remains permanently open access under the terms of the Creative Commons Attribution License 4.0 International License

\begin{abstract}
Currently, education globally is very challenging and experiencing rapid development that requires the educator to transform the way of teaching. Few empirical studies show that educator have yet to optimize the use of digital technologies in their educational practice, although a lot of training initiatives had been done. Therefore, the aim of this study is to explore whether there are any issues with digital technology training specifically in a post-secondary education institution of Malaysia. A qualitative approach using comparable case selection under general sampling strategies was implemented to scrutinize challenges of digital technology training based on trainer perceptions. Five interviews data were collected, four of them, right after digital technology training took place and the other one was a representative from the ministry, which data is used to support the information. A thematic analysis using thematic map technique was used to produce the related theme. The results from open coding showed 48 codes were analyzed to form ten categories. Ten categories were classified based on Social Cognitive Theory (SCT) lens then organized into personal, behavior and environmental factor that work reciprocally. Saturated themes were found from frequency table help to developed a conceptual framework of digital technology training. The finding of this study gives meaningful insights for future investigation developing a digital technology training framework for future-ready educators.
\end{abstract}

Keywords Digital Technology Training; Digital Technology; Preliminary Investigation, Educator Training

\section{Introduction}

Digital revolution brings more disruption where a lot of radical changes occur simultaneously, the speed is faster than ever, the breath and the depth are wider and deeper (Shwab, 2016). Education is one of the crucial fields that had been discussed in numerous studies and debates by the leaders and decision-makers. Time constraint, cost, technical support and limitation of infrastructure for the educator applying digital technology in their teaching and learning had been discussed decades ago (Haydn and Barton, 2008; Firmin and Genesi, 2013). However, as educators in order to become more technically competent, the shift towards flexible (Firmin and Genesi, 2013) digital training opportunities (Y. Qismullah et al., 2015) is necessary. This is due to the evolvement of a cyberphysical era that affects education tremendously. Educators must be prepared to face challenges in future education and digital technology shift. Most studies including World Economic Forum emphasize reskilling relearning in order for educators to equipping themselves with better digital technology skills (WEF, 2017). Some said educators are unable to impart foundational literacy skills knowledge and literacy education techniques to the future generation when they themselves have not received adequate training (Barnes et al., 2018).

Malaysia as a fast-growth developing country showing the serious commitment to position Malaysia as a highperforming education system in thirteen years by implementing Malaysia Education Blueprint 2013-2025 (MEB 2013-2025) to improve the quality of education and provide support to overall system (MEB Annual Report, 2015) including training. Although extensive endeavor had been done by the ministry, the performance for 5 years (2013 - 2017) seems to be slow. Educators are failing to take advantage of the opportunities presented by digital technology around them for their professional development (Chao, 2015). Umar \& Hassan (2015) said the integration 
of digital technology among Malaysian educators is still low while this fact also agreed by (Gil-Flores et. al, 2017). Despite the facts that many developed countries had provided the best digital technological infrastructure, digital technology policies and collaboration with private industries (Gil-Flores, Rodríguez-Santero, and TorresGordillo, 2017), but to sustain the utilization of digital technology into teaching and learning is still low (Dhir, 2019; Igwe et. al, 2019). Educators still think that training is needed to improve their knowledge and skills also to build their confidence (Cheok et. al, 2017).

Most of the studies on challenges of digital technology training were concentrate on specific software or hardware or tools that they use in assisting their teaching practice such as Learning Management System (LMS) (Adinugroho et. al, 2015; Sriprasertpap, 2015; Cheng \& Yuen, 2018), Massive Open Online Courses (MOOC) (RamírezMontoya et. al, 2015; Kaveri et. al, 2016) and online learning (Cheok, Wong and Ahmad Fauzi Ayub, 2017; Christensen and Knezek, 2017). However, this study will discover the general challenges of a trainee who training in using digital technology from trainer perspective right after the training occurred. This is to collect authentic reason arise during specific digital technology training.

\subsection{Objectives}

The aim of the study is to explore whether is there any issue with digital technology training in post-secondary education institution of Malaysia. Focusing on the main purpose, two objectives had been constructed for this study, (1) Identify the challenges of digital technology training for an educator (2) to identify the most suitable theory driven by the attributes. The answers may contribute to future studies. There may be some other useful information derive from the result, it may be collected as supportive information for the research.

\subsection{Research Questions}

There are 3 research questions that help this study.

- What are the challenges in training educators for digital technology?

- What is the most suitable theory that can derive based on the categories or themes?
What framework can assist in future research?

\section{Literature Review}

Digital technology in this research defined as any use of computer and technology include software, hardware, digital tools and applications, also digital media such as digital video audio, video game, web pages, and websites and including social media, data and databases, and electronic books that were used to assist strategies to support teaching and learning. (ZhiMin Xiao \& Maria Katsipataki, 2012, Report by Education Endowment Foundation, 2019).

Most of the previous studies emphasize on how digital technology can help to teach and learn such as effectiveness of the tools used (Aebersold et al., 2018; Karyotaki \& Drigas, 2016; Scholtz, et al., 2016), teaching strategy using digital tools (Andersen et al., 2018; Torres, 2018; Hauge, 2017; Heitink et al., 2016). A lot of studies mention that training (Aebersold et al., 2018; Bilal, Guraya, \& Chen, 2017; Gandomani et. al, 2015)is one of the crucial factors to make sure educators are on track in developing or upgrading their digital competence, knowledge, and skill in digital. However, the integration of digital technology into teaching and learning are still out of numbers (Cheok, Wong, \& Ahmad Fauzi Ayub, 2017; Zhang et. al, 2017; Instefjord \& Munthe, 2017; Kimiloglu et. al, 2017; Domingo \& Garganté, 2016; Baş et. al, 2016; Paraskevas et. al, 2015). Some of the studies suggested integrating a robot or artificial intelligent (AI) in training (Kimiloglu et. al, 2017; Paraskevas et. al, 2015).

Stoffregen et al., (2016) suggest doing more research had to be done on discovering challenges digital technology training. While Kimiloglu et. al, (2017) recommends constructing qualitative research to delve deeper into perceptual issues, especially resistance barriers to find out ways to overcome them. Therefore, in providing insight into the current issue in educators' digital technology training, a qualitative interview had been done to gain momentum as a mode of inquiry. This study focus showing step by step how the qualitative interview being analyzed. The process of data analysis was important to this study as it is used to identify the problem in digital technology training. In this section, research reveals the technique used in this study. 
Table1. Seven Steps of Research Interview (Adapted Braun \& Virginia, 2006)

\begin{tabular}{lll}
\hline & Phase & \\
\hline $\mathbf{1}$ & Thematising & It refers to the formation of research questions as well as the theoretical determination of research. \\
\hline $\mathbf{2}$ & Designing & $\begin{array}{l}\text { It involves planning on methods and techniques on how the interviews can be done. } \text { Research Operational } \\
\text { Planning }\end{array}$ \\
\hline $\mathbf{3}$ & Interviewing & $\begin{array}{l}\text { It refers to the type of interview that will be used in the interview process. In this study, researchers used } \\
\text { semi-structured interviews }\end{array}$ \\
\hline $\mathbf{4}$ & Transcribing & $\begin{array}{l}\text { It involves the process of preparation of materials for analysis purposes. The Interview material needs to } \\
\text { be converted into writing. In this research, oTranscribe used for this process. }\end{array}$ \\
\hline $\mathbf{5}$ & Analyzing & $\begin{array}{l}\text { The interview material was analyzed based on the objectives and theories in the study. Research once } \\
\text { again will use NVIVO 12 for this purpose }\end{array}$ \\
\hline $\mathbf{6}$ & Verifying & Analysis data need to be verified through validity and reliability procedures \\
\hline $\mathbf{7}$ & Reporting & Reporting on the findings on content analysis techniques in interviews. \\
\hline
\end{tabular}

Table2. Phases of Thematic Analysis (Braun and Clarke, 2006)

\begin{tabular}{|c|c|c|}
\hline & Phase & Description of the process \\
\hline 1 & $\begin{array}{l}\text { Familiarizing yourself } \\
\text { with your data: }\end{array}$ & Transcribing data (if necessary), reading and re-reading the data, noting down initial ideas. \\
\hline 2 & $\begin{array}{l}\text { Generating initial } \\
\text { codes: }\end{array}$ & $\begin{array}{l}\text { Coding interesting features of the data in a systematic fashion across the entire data set, collating data } \\
\text { relevant to each code. }\end{array}$ \\
\hline 3 & Searching for themes: & Collating codes into potential themes, gathering all data relevant to each potential theme. \\
\hline 4 & Reviewing themes: & $\begin{array}{l}\text { Checking if the themes work in relation to the coded extracts (Level 1) and the entire data set (Level 2), } \\
\text { generating a thematic 'map' of the analysis. }\end{array}$ \\
\hline 5 & $\begin{array}{l}\text { Defining and naming } \\
\text { themes: }\end{array}$ & $\begin{array}{l}\text { Ongoing analysis to refine the specifics of each theme, and the overall story the analysis tells, generating } \\
\text { clear definitions and names for each theme. }\end{array}$ \\
\hline 6 & Producing the report: & $\begin{array}{l}\text { The final opportunity for analysis. Selection of vivid, compelling extract examples, the final analysis of } \\
\text { selected extracts, relating back of the analysis to the research }\end{array}$ \\
\hline
\end{tabular}

\subsection{Thematic Analysis}

Thematic analysis is not just a collection of extracts strung together with little or no analytic narrative (Braun and Clarke, 2006). Table 2 shows the phase of thematic analysis used in this research that will elaborate in section 4 with more details. Braun \& Clarke (2006). The thematic analysis defines as locating in relation to other qualitative analytic methods that search for themes or patterns, and in relation to different epistemological and ontological positions. They also argue that thematic analysis is a flexible analysis that should be considered as a method in its own right.

\subsection{Future Ready Educator}

The word of "Future Ready" is a free, bold word to represent new efforts to maximize digital learning opportunities. It was formally introduced by a combination work from Digital Learning Specialist, Washington County School District (UT) Future Ready Schools (https://futureready.org). In order to prepare the future generation to be a life-long learner, as a role model, educators must first become them (a life-long learner). Educators must have the innovative, positive and flexible mindset (Chua \& Chua, 2017; Tarabasz, et al., 2018; Fiford, 2018), adaptable attitude and agile response to change (Aanestad, 2016; Dikert et al., 2016; Longmuß \& Höhne, 2017) to support a flexible education environment
In this research, Future Ready Educator define as an educator who is ready and fit to produce future generation, being flexible adapting future changes in preparing themselves to foster 21 centuries, cyber-physical future world and also sustaining their knowledge and skills in developing students who are ready to face the fourth industrial revolutions.

\section{Methodology}

The use of qualitative interviews is a well-established approach in information systems, psychological, management, and other social science studies. Qualitative process in this research involves three main steps namely (1) Planning (2) Data collection (3) Data analysis. Research planning is important to identify who are our best samples to become our informant; that can give a better answer to what we are searching for.

The research involved one of the post-secondary or pretertiary institutes in Malaysia where digital technology training was held. On top of that, we also interview one representative from the organization responsible for the training in the ministry. As for the preliminary investigation, the study wants to investigate the challenges of digital technology training, therefore all possible answers were recorded and the theme that saturated will be chosen as factors to build the initial framework. Figure 1 shows how the qualitative approach was implemented to 
meet the purpose of the research investigation.

\subsection{Samples}

The main reason the researcher chooses only one institution because we only want to explore either there are any issues in digital technology training that exist in that particular organization. A researcher wants to understand deeply what are the challenges that cause digital technology training issues. There are various sampling strategies available in the qualitative approach. In this study, researchers focus on one institution using comparable case selection under general sampling strategies (Matthew B. Miles, 2014); where the researcher chooses the only trainer as our informant. Comparable case selection emphasized in choosing informants with the same relevant characteristic. They are all trainers who trained the educators during the digital technology training course held in that particular institution. Although in this study we only focus on the trainer, the researcher decided to have another representative from the training management in the ministry to get supportive information. The trainers were the one who handles the training.

\subsection{Material}

The qualitative approach offers an effective way of understanding the current situation. The material used in this study was an interview protocol. Two types of interview questions we developed to organize two different interview sessions. One used for the trainers while the other used for a representative from an organization that responsible for providing digital technology training to educators.

\subsection{Defining the Case}

Miles \& Huberman (1994), emphasize the main focus and set the case boundaries as sampling, setting focus a particular institution which handling the digital technology training course. The research interview was done specifically after the end of the training session. This helped in providing actual feedback from a specific event.

\subsection{Data Collection}

The interview was conducted in the native language (Malay Language) as it makes the communication between both parties easier and more comfortable for both the informant and the researcher. To strengthen the precision, validity, stability, and trustworthiness of the finding, the researcher had done the member check to reconfirm the words coded are a match with what the informants mean. After a member check was done, then the researcher started with data analysis using thematic analysis assisted by NVIVO 12 as the tool.

\subsection{Research Operational Plan}

Creating a research operation plan helped in making the qualitative approach smoothly implemented. The idea came across when Miles \& Huberman (2014) emphasize building a conceptual framework. The aim of this preliminary study is just to get the initial idea for future research, a conceptual framework is not necessary, however, the research operation plan may do the same function. Figure 1 shows the flow of an operational research plan where the first step is to produce the main objective. A semi-structured interview question was created as a guideline towards achieving the objective. Theoretical Data Sampling is a very good strategy for validity and trustworthiness (Matthew B. Miles, 2014). This research focus on the feedback of a specific digital technology training from a trainer's perspective, the steps of adding a question or getting extra information is after transcribing took place.

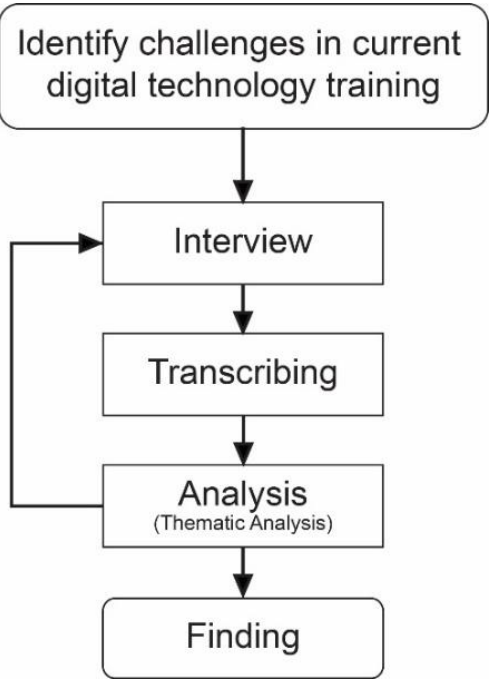

Figure 1. Research Operational Planning

Figure 1 shows how this study was conducted. Four trainers who directly involved with digital technology training were interviewed. Then the process of transcribing using otranscribe (https://otranscribe.com/), an easy and free transcribing website. After transcribing, reading and reread the whole transcript helped to get ideas in codding. Then thematic analysis was used to analyze all four transcripts. The thematic analysis was driven by this particular research question mention in 1.2. A member check was done as informant feedback or validation. This is a technique used to help improve the accuracy, credibility, validity, and trustworthiness of a study. In this study, the researcher has two loops of collecting interview data. From the first analysis, the researcher got from trainers interview, the researcher then constructed another interview questions for a representative from the training department in ministry. This process is shown as an arrow up on the left in figure 1. The interview's purpose was to 
extract supportive information about digital technology training after the first interview set. Then the result for both analysis act as our final finding.

\section{Results and Findings}

After transcribing the voice recording material and convert the audio data into text data. Then only the analysis process took place. The researcher applies thematic analysis introduced by Braun \& Virgina (2006) where there are 6 phases should be followed (Table 2.1) to define suitable theme related to our research objectives based on research questions.

\subsection{Phase 1: Familiarizing yourself with your data}

At this phase, the researcher focus on what we are going to identify. Immersion usually involves 'repeated reading' of the data, and reading the data in an active way. Searching for meanings, patterns and so on. In this research, during the process of transcription, although it is time-consuming, frustrating, and at times boring, the process is one of the ways to start familiarizing with the data (Riessman, 1993). Then, read through the entire data set at least once before begin coding, as ideas and identification of possible patterns will be shaped as you read through. This phase is very important to get ideas and a pattern of the transcripts that we were reading.

\subsection{Phase 2: Generating Initial Codes}

In this phase, the researcher familiarized herself and an initial list of ideas on the challenges of digital technology training. This phase then involves the production of initial codes from the data. The basic idea of the code also comes from the previous information from the literature review. The research found some similarities between the pattern in the transcript and identified factors from the earlier literature. This helped the process of coding. This study using NVIVO 12 as a tool to generate codes. Besides, factors of digital technology training in previous studies, data were coded based on the research questions as mention in 1.2. Forty-eight (48) codes were first produced on challenges of digital technology training. These codes were literally interpreted directly from the transcript.

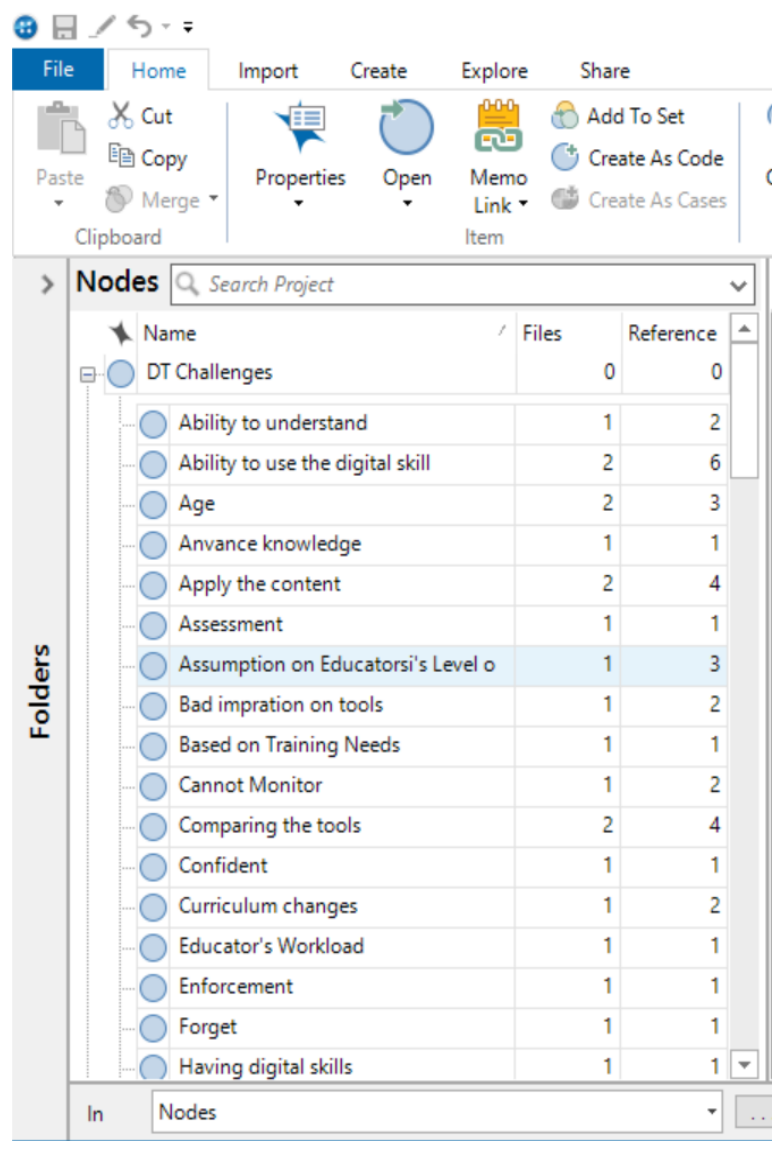

Figure 2. Example of how data being coded into nodes in NVIVO12

\subsection{Phase 3: Searching for Themes}

The steps begin when all data have been initially coded and collated, have a long list of the different codes that you have identified across the data set. This phase, refocuses the analysis at the broader level of categories, rather than codes, involves sorting the different codes into a potential category, and collating all the relevant coded data extracts within the identified themes. Followed by an initial map being drawn to capture the initial theme. In this study, all (48) initial codes again being analyzed into a set of categories. Braun \& Clarke (2006) explained, to make it look simple and easy to understand, the categories simplify and represent a map. Figure 3 shows the Thematic Analysis Initial Map for the challenges of digital technology training for educators. 
Figure 3 shows the initial thematic map developed using NVIVO 12 using the initial coding process. There are 10 categories represent the challenges that occur in particular digital technology training implemented by a group of trainers in a specific post-secondary institution in Malaysia. From 48 initial codes, 10 categories were constructed by combining codes according to their similarity. Ten categories showed a rectangular shape in the diagram. The 10 categories are (1) infrastructure, (2) Mindset, (3) Negative Attitude, (4) Trainers Competency, (5) Training Strategy, (6) Assessment, (7) Professionalism, (8) Motivation, (9) Poor of Training Development and (10)
Level of Digital Competency. Some of the categories are also a code but some of them are not. After generating the initial thematic map three (3) codes were eliminated, as we go through again thematic analysis only based on the research questions. The three eliminated codes were not representing the challenges of digital technology training. The three eliminated codes were self-learning, curriculum change, and type of training. Beside authentic challenges, any other words mentioned in the interview interpreted as threats coded as other supporting information. These codes may help in formularizing attributes to build the initial framework.

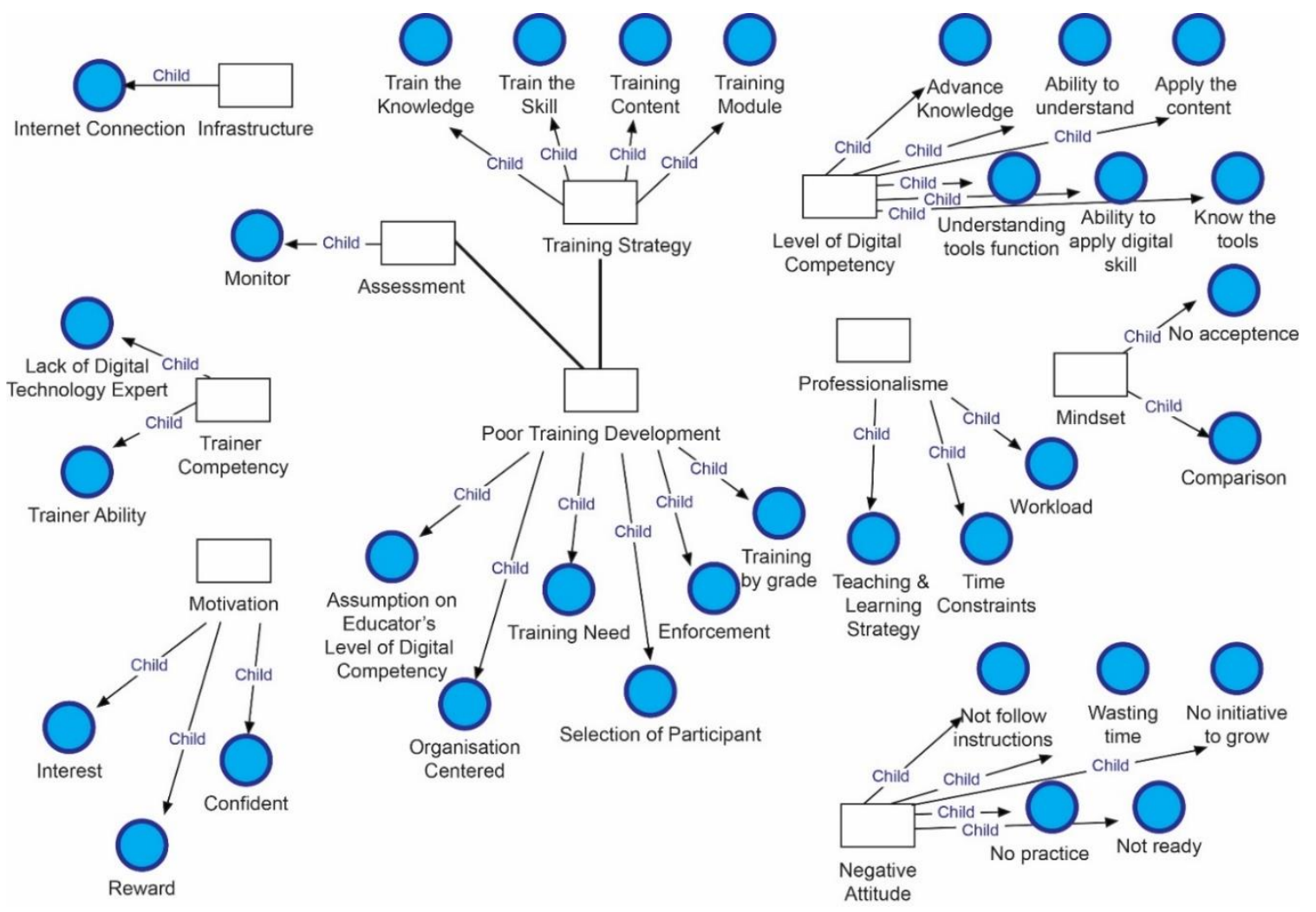

Figure 3. Initial Thematic Map for Challenges of Digital Technology Training for Educator.

Table 3. Frequency Table according to Challenges in Digital Technology Educators Training

\begin{tabular}{|c|c|c|c|c|c|c|}
\hline Categories & $\mathrm{O} 1$ & $\mathrm{~T} 1$ & $\mathrm{~T} 2$ & T3 & $\mathrm{T} 4$ & $\begin{array}{c}\text { Total } \\
\text { Frequency }\end{array}$ \\
\hline Assessment & 1 & 4 & 1 & 1 & 1 & 8 \\
\hline Intrastructure & 1 & & & 1 & & 2 \\
\hline Level of Digital Competency & 1 & 9 & 9 & 7 & 3 & 29 \\
\hline Mindset & & 2 & & 3 & & 5 \\
\hline Motivation & & 8 & & 1 & & 9 \\
\hline Negative Attitude & 1 & 3 & 2 & 8 & 1 & 15 \\
\hline Poor Training Development & 9 & & & & 1 & 10 \\
\hline Professionalism & 1 & 4 & 1 & 1 & 2 & 9 \\
\hline Trainer Competency & 3 & & 1 & & 1 & 5 \\
\hline Training Strategy & & 2 & & 2 & & 4 \\
\hline
\end{tabular}


A table of analysis has been subjected to considerable to clarify themes according to the participant (Görke et al., 2017). Table 3 shows a framework matrix done in NVIVO 12 , view as a frequency table for challenges of digital technology training said by the informant.

Table 3 shows a number of frequency sentences being coded for every informant. What stands out in the table is the Level of Digital Competency for educators to be the most frequent issue that been highlighted, followed by a Negative Attitude and Poor Training Development. The frequency shows the number of codes being said or mention for each informant. Some of the codes mention by certain informants repeatedly. The level of Digital Competency shows the most important factor to be a challenge to digital technology training. This means it is crucial for educators to know their level of digital competency before attending any digital technology training. Therefore the appropriate training will be facilitating the appropriate audience (trainee).

Obviously, Poor Training Development said repeatedly 9 times by the representative from the training department in the ministry. The department is responsible for planning and developing educators' training. As the implementation took place they reflect and realize the impact of training development may be the factors of training challenges. Referring to Figure 3 and Table 1, what is stated in Poor Training Development, the educator was chosen by grade in their service. However, the potential to adapt knowledge of digital technology can not only be determined by the experience in teaching (Kalogiannakis, 2010). Other than that, trainee also is chosen by subject, referring which subject need to use digital technology in their syllabi such as Computer Science, Science, English, ICT, and Technology Design (Rekabentuk Teknologi). The impact of improper selection of the trainee among the educators may lead to a few challenges; that are negative attitude, do not have to believe in using digital technology, lack of digital technology competency, and lack of knowledge (Morris, 2010; Bindon, 2017; Kimiloglu, Ozturan and Kutlu, 2017). Without a specific guideline in choosing participant of the training, transfer of training process must be difficult, hence the objective of the training may not be achieved (Ma et al., 2018). As a result, there still educators who felt uncomfortable using digital technology as their teaching aid. Therefore, Poor Training Development category reciprocal to Mindset and Negative Attitude.

The least frequency being highlighted is the Infrastructure and Training Strategy. Although a few studies argued the importance of infrastructure training digital technology (Gil-Flores et. al, 2017), however in this study, infrastructure does not give important insight. This may be the trainer who is the informant told their perspective relates only to the particular training that they just involved in.

Another interesting about the data in Table 3 is there are four (4) categories highlighted by all the informants. This considers the point of saturation that had been met. Those four categories are Assessment, Level of Digital Competency, Negative Attitude, and Professionalism. These are the categories act as the biggest challenges in digital technology training for the course arranged by the particular training. These attributes are not generalized for every challenge of digital technology training. These categories also will be chosen as an attribute to build a conceptual framework.

\subsection{Phase 4: Reviewing Theme}

According to Braun, Virginia, (2006), some initial codes may form main themes, whereas others may form subthemes, and others still may be discarded following what being subject of interest for the research. At this point, we started to have a sense of the significance of individual themes. This will be discussed in phase 5, after explanation on relationship cause and effect is drawn in figure 3.

Four trainers were interviewed right after a digital technology training session was held. The other participant was from the organization that responsible for providing digital technology training generally to the educators. There is a slightly different set of structured questions given to organizations' representatives and the trainers. Challenges of digital technology training are the main questions for the trainers and, a few further questions to formulate the training strategy had been asked to organizations' representatives. Figure 4 is showing categories that related to one another. The number is shown what is the similarity of those categories. Current Digital Technology Training has no guidelines in choosing their participants to be a trainee. Educator was chosen by grade in their service. However, the potential to adapt knowledge of digital technology can not only be determined by the experience in teaching (Kalogiannakis, 2010). Other than that, trainee also is chosen by subject, referring which subject need to use digital technology in their syllabi such as Computer Science, Science, English, ICT, and Technology Design (Rekabentuk Teknologi). As a result, there still educators who felt uncomfortable using digital technology as their teaching aid.

No Assessment or evaluation from the management may lead to no continually using digital technology in educational practice. As we are aware that digital technology changes super fast. Furthermore, the organization may not put any effort to organize a continually training; administer may assume educators are well equipped themselves with digital competency. The main problem here is, digital technology is exponentially changed. We may need a sustainable training to improve digital technology competency from time to time (Paper, 2017). However, without a specific training framework may affect the readiness of the educator in changing themselves into better behavior to be future-proof educators. 
Challenges occur in the current digital technology training were coded. The codes were identified based on the participants' responses. Referring to figure 3, ability to understand, understanding the function of tools, ability to use the digital skill, advance knowledge had been embedded in lack of competency as according to (Wood and Bandura, 1989) competency is a combination of knowledge and skills that lead to the ability to do work efficiently. According to the management field, knowledge, skills, and attitude (KSA) combine as competency (P. Nick Blanchard, 2013).

\subsection{Phase 5: Defining and Naming Themes}

The challenges were identified to improve training to equipped current educators to become future-ready educators. Then the new thematic map which eliminates a few items based on the suitable theory that match. Social
Cognitive Theory (SCT) was used as a basic lens in this study. Figures 4 show the process of numbering the categories into a new theme.

The three designated themes also supported based on Social Cognitive Theory (SCT) (Bandura, 2001) were personal, behavior and environment factors. From the analysis, after numbering on the categories, the new theme. Number (1) shows personal factors, number (2) shows behavior factors and (3) is for environmental factors. These categories are arranged according to suitable theory is for a guideline for future research. A reciprocal determination diagram was drawn, and the element arranged accordingly. In this research, we decided the most suitable theory for determining the challenges of digital technology training was the best match with Social Cognitive Theory(SCT) by Albert Bandura (Bandura, 1991; Bolt et.al, 2001). Figure 5 shows the arrangement of the theme onto three (3) major factors in SCT.

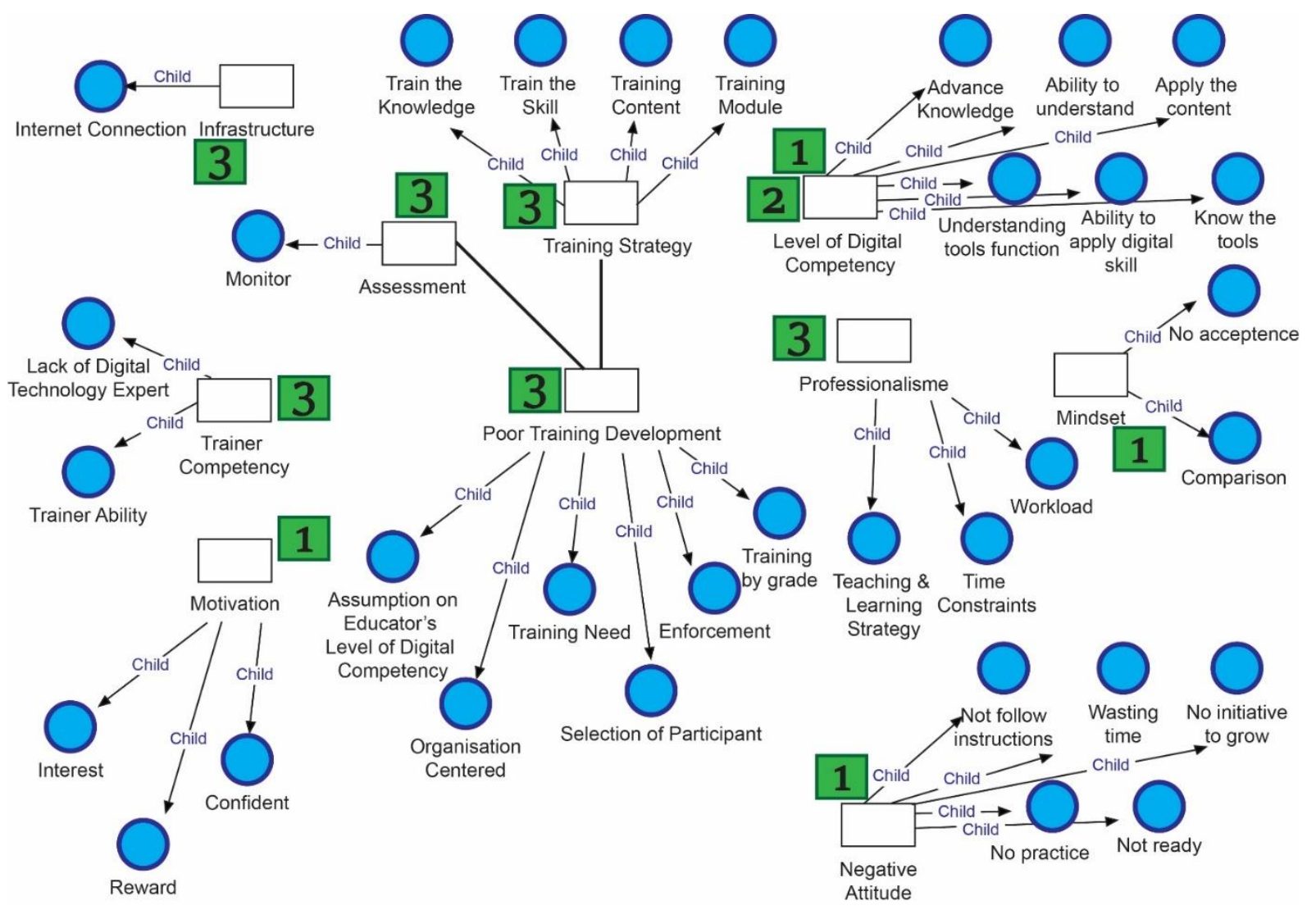

Figure 4. Cause and Effect Thematic Analysis Map 


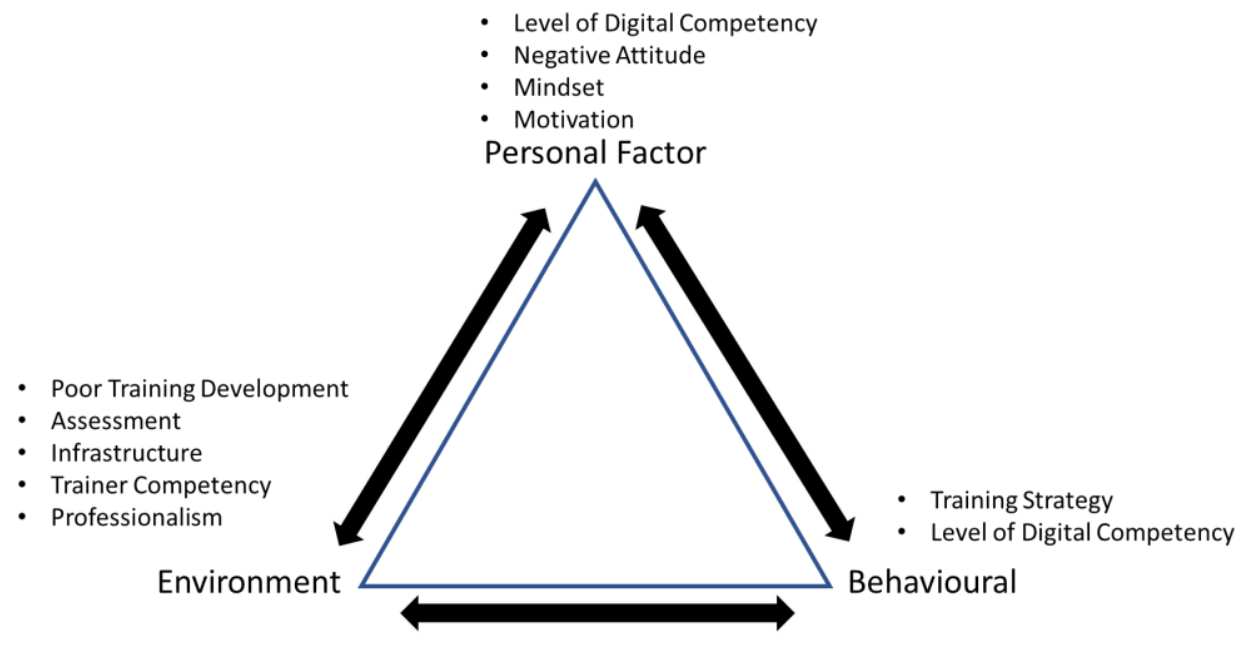

Figure 5. Social Cognitive Theory Reciprocal Determinism for Challenges in Digital Technology Training for Educators

Figure 5 shows the organization of the themes into Social Cognitive Theory. The collection of related categories forms a suitable theme. This technique was referred to as Matthew B Miles, (1994). In information systems studies, there are arguments that look at digital technology training in different theoretical perspectives (Author et al., 1999). In recent Information System (IS) studies of digital technology training, researchers are debating on Technology Acceptance Model (TAM) (Cheng \& Yuen, 2018), Unified Theory of Acceptance Use of Technology (UTAUT) (Gil-Flores et al., 2017), DeLone and McLean IS Success Model (Kimiloglu et al., 2017) that focus on quality satisfaction, Situated Learning Theory (SLT) (Aebersold et al., 2018) for actual gamification training, Constructivist Learning (Alt, 2018; Zhang, Liu, Chen, Wang, \& Huang, 2017). Nevertheless, in this study, we organized the identified theme into common criteria for Triadic Reciprocal Determinism factors as shown in Figure 5. What stands out is the Level of Digital Competency has to be in both personal and behavioral factors.

Although we had categorized the identified theme into Triadic Reciprocal Determinism, what will be used as insight for future study were the themes that had reached saturation criteria from all the informants as shown in Table 4 . The four (4) highlighted themes considered as a component of digital technology training in future research. Those themes were then formulated a conceptual framework shown in Figure 6.

Table 4. Frequency Table according to Challenges in Digital Technology Educators Training

\begin{tabular}{|c|c|c|c|c|c|c|}
\hline Categories & O1 & $\mathrm{T} 1$ & $\mathrm{~T} 2$ & $\mathrm{~T} 3$ & $\mathrm{~T} 4$ & $\begin{array}{c}\text { Total } \\
\text { Frequency }\end{array}$ \\
\hline Assessment & 1 & 4 & 1 & 1 & 1 & $8 \checkmark$ \\
\hline Intrastructure & 1 & & & 1 & & 2 \\
\hline Level of Digital Competency & 1 & 9 & 9 & 7 & 3 & $29 \checkmark$ \\
\hline Mindset & & 2 & & 3 & & 5 \\
\hline Motivation & & 8 & & 1 & & 9 \\
\hline Negative Attitude & 1 & 3 & 2 & 8 & 1 & $15 \checkmark$ \\
\hline Poor Training Development & 9 & & & & 1 & 10 \\
\hline Professionalism & 1 & 4 & 1 & 1 & 2 & $9 \checkmark$ \\
\hline Trainer Competency & 3 & & 1 & & 1 & 5 \\
\hline Training Strategy & & 2 & & 2 & & 4 \\
\hline
\end{tabular}




\section{Challenges of Digital Technology Training for Educators}

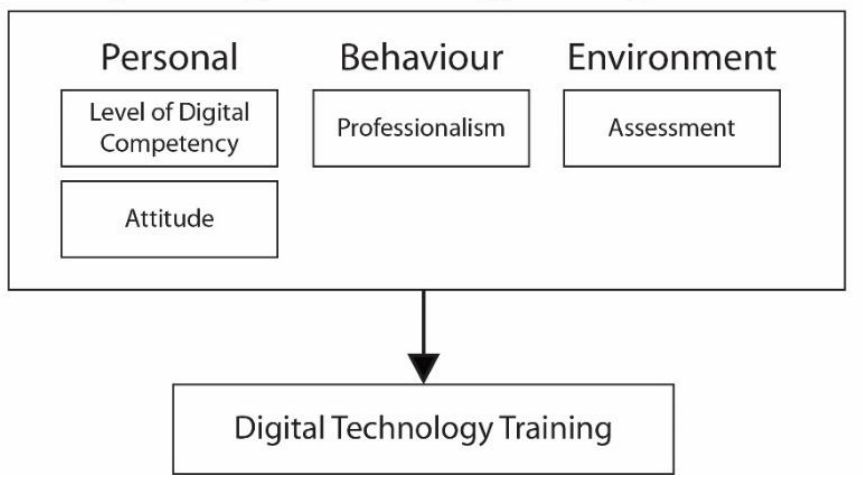

Figure 6. Conceptual Framework for Digital Technology Training.

\subsection{Discussion}

As a discussion from the result of thematic analysis, research had to draft a conceptual framework that draws the issue found in discovering attributes needed to train futureready educators. According to (Braun, Virginia, 2006), phase 6 is producing a report that will be done in this discussion section. According to Bandura, (2001), there were three main factors that reciprocal to each other which then influence new behavior. As thematic analysis is a flexible method, you also need to be clear and explicit about what you are doing, and what you say you are doing needs to match up with what you actually do. As we have shown throughout this paper, thematic analysis is not a complex method. By using 15 check-list of thematic analysis (Braun, Virginia, 2006), we manage to construct a final conceptual map based on social cognitive theory as shown in Figure 6.

\section{Conclusions}

In conclusion, this study is a preliminary study to find out the existence of authentic issue related challenges of digital technology training for educators. A qualitative interview used as the main method to gather data related to challenges of current digital technology training and any supportive problem that can be input for future research. This study was conducted after a certain finding derived from a review of the previous study. Four trainers were interviewed to speak their perspectives on the challenges of digital technology training. After the final finding from those for the trainer, another interview was done to understand some information from a represented from the training department in the ministry. The department is responsible for handling training for educators. Another thematic analysis being done then data from informants which have different roles were combined and form a final finding. The finding reveals 10 categories out of 47 codes. The categories help to match a suitable for future research. Finally, the themes from categories that reach saturation were chosen to be the attribute in building a conceptual framework. This study is not aiming to do any generalization because it was done a particular postsecondary education institution in Malaysia. The aim was to identify, is there any problem in digital technology training in post-secondary institutions. The final answer showed that the research on digital technology training is good to research for. The process was rigorously done and the step of getting the result was explained. The analysis and the result of this study sought to help in structuring the problem statement for future research.

\section{REFERENCE}

[1] Aanestad, M. (2016) 'Scandinavian Journal of Information Systems How IS can become more Agile and Relevant', 28(2), pp. 2-6. Available at: http://aisel.aisnet.org/sjis\%0A http://aisel.aisnet.org/sjis/vol28/iss2/4.

[2] Adinugroho, T. Y., Reina and Gautama, J. B. (2015) 'Review of Multi-platform Mobile Application Development Using WebView: Learning Management System on Mobile Platform', Procedia Computer Science. Elsevier Masson SAS, 59(Iccsci), pp. 291-297. DOI: 10.1016/j.procs.2015.07.568.

[3] Aebersold, M. et al. (2018) 'Interactive AnatomyAugmented Virtual Simulation Training', Clinical Simulation in Nursing. Elsevier Inc, 15, pp. 34-41. DOI: 10.1016/j.ecns.2017.09.008.

[4] Andersen, P. et al. (2018) 'Snapshots of Simulation: Innovative Strategies Used by International Educators to Enhance Simulation Learning Experiences for Health Care Students', Clinical Simulation in Nursing. Elsevier Inc, 16, pp. 8-14. DOI: 10.1016/j.ecns.2017.10.001.

[5] Bandura, A. (1991) 'Social Cognitive Theory of SelfRegulation', in.

[6] Bandura, A. (2001) 'SOCIAL C COGNITIVE THEORY: An Agentic Perspective', Annual Review of Psychology, 52(1), pp. 1-26. DOI: 10.1146/annurev.psych.52.1.1.

[7] Barnes, A. E. et al. (2018) 'Improving teacher training in Ethiopia: Shifting the content and approach of pre-service 
teacher education', Teaching and Teacher Education. Elsevier Ltd, 70, pp. 1-11. DOI: 10.1016/j.tate.2017.11.004.

[8] Baş, G., Kubiatko, M. and Sünbül, A. M. (2016) 'Teachers' perceptions towards ICTs in the teaching-learning process: Scale validity and reliability study', Computers in Human Behavior, 61, pp. 176-185. DOI: 10.1016/j.chb.2016.03.022.

[9] Bilal, Guraya, S. Y. and Chen, S. (2017) 'The impact and effectiveness of faculty development program in fostering the faculty's knowledge, skills, and professional competence: A systematic review and meta-analysis', Saudi Journal of Biological Sciences. The Authors. DOI: 10.1016/j.sjbs.2017.10.024.

[10] Bindon, S. L. (2017) 'Professional Development Strategies to Enhance Nurses' Knowledge and Maintain Safe Practice', AORN Journal. Elsevier, 106(2), pp. 99-110. DOI: 10.1016/j.aorn.2017.06.002.

[11] Bolt, M. A., Killough, L. N., and Koh, H. C. (2001) 'Testing the Interaction Effects of Task Complexity in Computer Training Using the Social Cognitive Model', Decision Sciences, 32(1), pp. 1-20. DOI: 10.1111/j.15405915.2001.tb00951.x.

[12] Braun, Virginia, V. C. F. (2006) 'Using thematic analysis in psychology Thematic', 3(2006), pp. 77-101. DOI: 10.1191/1478088706qp063oa.

[13] Braun, V. and Clarke, V. (2006) 'Using thematic analysis in psychology’, 0887(January), pp. 77-101. DOI: 10.1191/1478088706qp063oa.

[14] Chao, G. M. (2015) 'Impact of Teacher Training on Information Communication Technology Integration in Public Secondary Schools in Mombasa County', 5(4), pp. 77-94. DOI: 10.5923/j.hrmr.20150504.01.

[15] Cheng, M. and Yuen, A. H. K. (2018) 'Student continuance of learning management system use: A longitudinal exploration', Computers and Education. Elsevier, 120(June 2017), pp. 241-253. DOI: 10.1016/j.compedu.2018.02.004.

[16] Cheok, M. L., Wong, S. L. and Ahmad Fauzi Ayub (2017) 'Teachers' perceptions of e-learning in Malaysian Secondary Schools', Malaysian Online Journal of Educational Technology (MOJET), 5(2), p. 14.

[17] Christensen, R. and Knezek, G. (2017) 'Readiness for integrating mobile learning in the classroom: Challenges, preferences and possibilities', Computers in Human Behavior. Elsevier B.V., 76, pp. 112-121. DOI: 10.1016/j.chb.2017.07.014.

[18] Chua, Y. P. and Chua, Y. P. (2017) 'How are e-leadership practices in implementing a school virtual learning environment enhanced? A grounded model study', Computers and Education. Elsevier Ltd, 109, pp. 109-121. doi: 10.1016/j.compedu.2017.02.012.

[19] Dhir, S. (2019) 'The changing nature of work, leadership, and organizational culture in future-ready organizations', CMC Senior Theses, p. 64. Available at: https://scholarship.claremont.edu/cmc_theses/2064.

[20] Dikert, K., Paasivaara, M. and Lassenius, C. (2016) 'Challenges and success factors for large-scale agile transformations: A systematic literature review', Journal of
Systems and Software. Elsevier Inc., 119, pp. 87-108. doi: 10.1016/j.jss.2016.06.013.

[21] Domingo, M. G., and Garganté, A. B. (2016) 'Exploring the use of educational technology in primary education: Teachers' perception of mobile technology learning impacts and applications' use in the classroom', Computers in Human Behavior, 56, pp. 21-28. doi: 10.1016/j.chb.2015.11.023.

[22] Firmin, M. W., and Genesi, D. J. (2013) 'History and Implementation of Classroom Technology', Procedia Social and Behavioral Sciences. Elsevier B.V., 93, pp. 1603-1617. doi: 10.1016/j.sbspro.2013.10.089.

[23] Forum, W. E. (2017) 'Realizing Human Potential in the Fourth Industrial Revolution An Agenda for Leaders to Shape the Future of Education, Gender and Work'. The USA, (January), p. 35. Available at: http://www3.weforum.org/docs/WEF_EGW_Whitepaper.p df.

[24] Gandomani, T. J. et al. (2015) 'The impact of inadequate and dysfunctional training on agile transformation process: A grounded theory study', Information and Software Technology. Elsevier B.V., 57(1), pp. 295-309. doi: 10.1016/j.infsof.2014.05.011.

[25] Gil-Flores, J., Rodríguez-Santero, J. and Torres-Gordillo, J. J. (2017) 'Factors that explain the use of ICT in secondaryeducation classrooms: The role of teacher characteristics and school infrastructure', Computers in Human Behavior. Elsevier Ltd, 68, pp. 441-449. doi: 10.1016/j.chb.2016.11.057.

[26] Görke, M. et al. (2017) 'Employee Qualification by Digital Learning Games', Procedia Manufacturing. The Author(s), 9, pp. 229-237. DOI: 10.1016/j.promfg.2017.04.040.

[27] Hauge, T. E. (2017) 'International Teacher Education: Promising Pedagogies (Part B)', p. i. doi: 10.1108/s1479368720150000025026.

[28] Haydn, T. and Barton, R. (2008) “"First do no harm": Factors influencing teachers' ability and willingness to use ICT in their subject teaching', Computers and Education, 51(1), pp. 439-447. doi: 10.1016/j.compedu.2007.06.001.

[29] Heitink, M. et al. (2016) 'Teachers' professional reasoning about their pedagogical use of technology', Computers and Education. Elsevier Ltd, 101, pp. 70-83. DOI: 10.1016/j.compedu.2016.05.009.

[30] Igwe, P. A., Okolie, U. C. and Nwokoro, C. V. (2019) 'Towards a responsible entrepreneurship education and the future of the workforce', International Journal of Management Education. Elsevier, (May), p. 100300. doi: 10.1016/j.ijme.2019.05.001.

[31] Instefjord, E. J. and Munthe, E. (2017) 'Educating digitally competent teachers: A study of the integration of professional digital competence in teacher education', Teaching and Teacher Education. Elsevier Ltd, 67, pp. 3745. DOI: 10.1016/j.tate.2017.05.016.

[32] Kalogiannakis, M. (2010) 'Training with ICT for ICT from the trainee's perspective. A local ICT teacher training experience', Education and Information Technologies, 15(1), pp. 3-17. DOI: 10.1007/s10639-008-9079-3. 
[33] Karyotaki, M. and Drigas, A. (2016) 'Online and other ICTbased training tools for problem-solving skills', International Journal of Emerging Technologies in Learning, 11(6), pp. 35-39. doi: 10.3991/ijet.v11i06.5340.

[34] Kaveri, A. et al. (2016) 'Decoding the Indian MOOC learner', Proceedings of the 2015 IEEE 3rd International Conference on MOOCs, Innovation and Technology in Education, MITE 2015, pp. 182-187. DOI: $10.1080 / 10916466.2016 .1202974$.

[35] Kimiloglu, H., Ozturan, M. and Kutlu, B. (2017) 'Perceptions about and attitude toward the usage of elearning in corporate training', Computers in Human Behavior. Elsevier Ltd, 72(2017), pp. 339-349. doi: 10.1016/j.chb.2017.02.062.

[36] Longmuß, J. and Höhne, B. P. (2017) 'Agile Learning for Vocationally Trained Expert Workers. Expanding Workplace-based Learning One Sprint at a Time', Procedia Manufacturing. The Author(s), 9, pp. 262-268. DOI: 10.1016/j.promfg.2017.04.003.

[37] Ma, F. et al. (2018) 'Factors influencing training transfer in the nursing profession: A qualitative study', BMC Medical Education. BMC Medical Education, 18(1), pp. 1-9. DOI: 10.1186/s12909-018-1149-7.

[38] Matthew B Miles, A. M. H. (1994) Qualitative Data Analysis. SAGE Publication Inc.

[39] Morris, D. (2010) 'Are teachers technophobes? Investigating professional competency in the use of ICT to support teaching and learning,, Procedia - Social and Behavioral Sciences, 2(2), pp. 4010-4015. doi: 10.1016/j.sbspro.2010.03.632.

[40] Paper, W. (2017) 'Realizing Human Potential in the Fourth Industrial Revolution An Agenda for Leaders to Shape the Future of Education, Gender and Work', (January).

[41] Ramírez-Montoya, M.-S., Hernández-Carranza, E.-E. and Romero-Corella, S.-I. (2015) 'Evaluation of Digital Didactic Skills in Massive Open Online Courses: a Contribution to the Latin American Movement', Comunicar, 22(44), pp. 81-90. DOI: 10.3916/C44-2015-09.

[42] Scholtz, B., Esterhuyse, M. and Dafoulas, G. (2016) 'a Process for Designing and Developing Inter- Active Learning Objects for Organisations', Mcis 2016.

[43] Sriprasertpap, K. (2015) 'The Development of Online Training Model for Srinakharinwirot University in Thailand', Procedia - Social and Behavioral Sciences. Elsevier B.V., 197(February), pp. 1913-1917. DOI: 10.1016/j.sbspro.2015.07.254.

[44] Stoffregen, J. D. et al. (2016) 'Barriers to open e-learning in public administrations: A comparative case study of the European countries Luxembourg, Germany, Montenegro, and Ireland', Technological Forecasting and Social Change, 111, pp. 198-208. DOI: 10.1016/j.techfore.2016.06.030.

[45] Tarabasz, A., Selaković, M. and Abraham, C. (2018) 'The Classroom of the Future: Disrupting the Concept of Contemporary Business Education', Entrepreneurial Business and Economics Review, 6(4), pp. 231-245. DOI: 10.15678/eber.2018.060413.

[46] Torres, H. G. (2018) 'The Misunderstood Link : Information
Security Training Strategy', pp. 1-5.

[47] Umar, I. N., and Hassan, A. S. A. (2015) 'Malaysian Teachers' Levels of ICT Integration and Its Perceived Impact on Teaching and Learning', Procedia - Social and Behavioral Sciences. Elsevier B.V., 197(February), pp. 2015-2021. doi: 10.1016/j.sbspro.2015.07.586.

[48] Wood, R., and Bandura, A. (1989) 'Social Cognitive Theory of Organizational Management', 14(3), pp. 361-384. 